EESTF NSV TEADUSTE AKADEEMIA TOIMETISED. XV́II KÖIDE

KEEMIA * GEOLOOGIA. 1968, Nr. 2

ИЗВЕСТИЯ АКАДЕМИИ НАУК ЭСТОНСКОИ ССР. ТОМ ХVII

ХИмИя - ГЕОЛОГИЯ. 1968. Nㅡ 2

C. $Б А У K O B ~$

\title{
КРИТЕРИИ ГЕОЛОГО-ПРОМЫШЛЕННОЙ ОЦЕНКИ ПРИБАЛТИИСКОГО СЛАНЦЕВОГО БАССЕЙНА
}

В решении проблемы рационального использования ресурсов Прибалтийско:о сланцевого бассейна важное значение имеют его геолого-технико-экономические факторы. В статье более подробно характеризуются факторы, осложняющие освоение бассейна, и обосновывается необходимость дополнительного и более детального их изучения в целях наиболее полного извлечения запасов при добыче и безопасного ведения подземных горных работ.

\section{Общие сведения. Народнохозяйственные и природные факторы оценки бассейна}

В состав Прибалтийского еланцевого бассейна (ПСБ) входят два месторождения промышленного значения: Эстонское и Ленинградское, граница между которыми проводится по административному признаку и проходит по р. Нарве. В установленных геологоразведкой промышленных границах бассейн прослеживается в широтном направлении по простиранию слоев (вдоль железнодорожной магистрали ЛенинградТаллин) на протяжении 200 км от меридиана г. Тапа в Эстонской ССР до меридиана ст. Веймарн в Ленинградской области, и в южном направлении - по падению слоев на протяжении 20-35 км, до широты северного берега Чудского озера.

На Прибалтийскнй сланцевый бассейн приходится более $3 / 4$ разведанных запасов категорий $\mathrm{A}+\mathrm{B}+\mathrm{C}$ и около 95\% общей добычи горючих сланцев СССР. Эстонское месторождение разрабатывается с 1916 года; до 1967 г. включительно на нем добыто 200 млн. т товарного сланца. Сейчас на месторождении имеется действующих девять шахт и два карьера и в стадии строительства находятся одна шахта и два карьера. В 1967 г. здесь добыто 16 млн. т сланца. Ленинградское месторождение разрабатывается с 1932 года; до 1967 г. включительно на нем добыто 50 млн. т товарного сланца. На месторождении работают четыре шахты. В 1967 г. здесь получено около 4 млн. т сланца (Вийлуп и др., 1967).

Горючие сланцы ПСБ, или по широко распространенному их названию - кукерситы, приурочены к отложениям лландейльского и кара- 
докского ярусов среднего ордовика, в которых они залегают среди тонко- и среднеслоистых мергелей, глинистых известняков, известняков и доломитизированных известняков в виде слоев мощностью от нескольких сантиметров до одного метра. Наиболее мощные и выдержанные по распространению слои кукерсита залегают в низах кукрузеского горизонта нижнего карадока, где несколько сближенных слоев кукерсита образуют единственный в разрезе сланценосной толщи ПСБ (общей мощностью около 30 м) промышленный пласт; на Эстонском месторождении это слои А, B, C, D, E и F, которым на Ленинградском месторождении соответствуют стратиграфически слои IV, III, II и I (индексация слоев дана снизу вверх). Собственно этот промышленный пласт кукерсита и образует полезную залежь ПСБ, восточная и южная границы которого определяются генетическим выклиниванием сланцевых слоев промпласта и одновременно фациальным замещением горючих сланцев мергелями и глинистыми известняками. Западная граница определяется также генетическим выклиниванием сланцевых слоев и одновременно фациальным замещением горючих сланцев керогенсодержашими известняками. Северная граница бассейна - эрозионная. Количество и мощность сланцевых слоев возрастают к средней части разреза сланценосной толщи и к центру площадного ее распространения. Именно в центральной части бассейна на площади 5 тыс. км ${ }^{2}$ и распространен промышленный пласт сланца с полезной мощностью больше 0,7 м. Судя по обрывающимся изопахитам промышленного пласта сланца у северной границы бассейна, можно предполагать, что современная, сохранившаяся от размыва площадь бассейна составляет около $2 / 3$ первоначальной, которая имела, по-видимому, очертания овала с длинной осью по линии Хельсинки-Новгород. В остальной части бассейна и в других частях разреза сланценосной толщи пока не установлено сланцевой залежи, представляющей в настоящее время практический интерес.

Современное народнохозяйственное значение ПСБ в развитии производительных сил северо-западных районов СССР определяется его большими запасами горючего сланца хорошего качества, доступными для дешевой добычи, и его местонахождением в густонаселенном районе страны с высокоразвитой промышленностью, где имеется постоянный большой спрос на электрическую энергию и где нет других, кроме ПСБ, крупных источников для ее производства. Многолетний опыт показал, что производство электроэнергии на крупных электростанциях из горючего сланца ПСБ на месте его добычи, оссбенно из сланца Эстонского месторождения, - рентабельно. Более $60 \%$ добываемого в настоящее время в Эстонии горючего сланца расходуется на выработку электроэнергии. Предусмотренный планом рост производства электроэнергии в Эстонии на ближайшие годы в 1,8 раза потребует увеличения добычи сланца по сравнению с достигнутым уровнем в 1,3 раза. Вырабатываемая в Эстонской ССР из горючего сланца электроэнергия идет не только на нужды самой республики, но в значительном количестве передается в Ленинградскую область и другие соседние районы. Кукерсит с успехом используется также и для термической переработки в целях получения жидкого и газообразного топлива и разнообразных химичсских продуктов, которые находят широкий сбыт и за пределами Эстонии. Данные Института горючих ископаемых СССР (Мельников, 1966) показывают, что горючие сланцы ПСБ занимают второе место после природного газа по расчетным затратам на добычу, переработку и использование основных видов топлива на 1970 год в среднем по СССР (см. табл. 1). 


\begin{tabular}{|c|c|c|}
\hline \multirow{2}{*}{$\begin{array}{l}\text { Наименование } \\
\text { топлива }\end{array}$} & \multicolumn{2}{|c|}{$\begin{array}{c}\text { Затраты по добыче, переработке } \\
\text { и использованию }\end{array}$} \\
\hline & $\begin{array}{c}p y \sigma / \tau \text { условного } \\
\text { топлива }\end{array}$ & $\%$ \\
\hline $\begin{array}{l}\text { Уголь ископаемый } \\
\text { Торф } \\
\text { Мазут } \\
\text { Сланец горючий } \\
\text { Газ природный }\end{array}$ & $\begin{array}{r}11,40 \\
9,76 \\
7,10 \\
6,44 \\
4,50\end{array}$ & $\begin{array}{r}100,0 \\
85,0 \\
62,1 \\
56,4 \\
39,5\end{array}$ \\
\hline
\end{tabular}

По состоянию на 1/I 1967 г. запасы горючего сланца в пределах ПСБ оценены в 5,5 млрд. $T$ по категориям $\mathrm{A}+\mathrm{B}+\mathrm{C}_{1}$ и в 6,0 млрд. $\tau$ по категории $\mathrm{C}_{2}$ (в том числе по Эстонсксму месторождению соответственно 4,4 млрд. $T$ и 4,1 млрд. $T$ ). Действующие шахты и карьеры обеспечены запасами на 20-30 лет. Балансовые запасы категорий $\mathrm{A}+\mathrm{B}+\mathrm{C}_{1}$ по действующим и строящимся шахтам и карьерам бассейна составляют около $30 \%$ от общих балансовых запасов тех же категорий, что указывает на большие потенциальные возможности дальнейшего развития здесь добычи сланца.

Наряду с большими запасами и выгодными географо-экономическими условиями промышленному освоению ПСБ способствуют его простое геологическое строение и в общем благоприятные горнотехнические условия разработки: промышленный пласт горючего сланца залегает здесь постоянно на одном стратиграфическом урсвне, неглубоко (от выходов на дневную поверхность до 130 м.) и практически горизонтально; пласт сланца имеет сплошное распространение, устойчив по мощности и выдержан по качеству в пределах одного шахтного поля или группы полей; боковые породы, представленные, как указыва́лось, мергелями и известняками, - крепкие, и вне зон геологических нарушений они относительно устойчивые против обрушения; шахты не опасны по газу, пыли и самовозгоранию сланца. Однако для более объективной геолого-промышленной оценки необходимо дать детальную характеристику бассейна по показателям, осложняющим его освоение, из которых основными являются: сложное строение промпласта, большая зольность сланца, неровности гипсометрии подошвы промпласта, интенсивно развитая трещиноватость и закарстованность промпласта и вмещающих пород, размывы промпласта по погребенным эрозионным долинам, обильное обводнение горных выработок и др.

\section{Строение промпласта}

Сложное строение промпласта сланца ПСБ характеризуется тонкослоистым переслаиванием кукерситов и известняков. На шахтах Эстонского месторождения из общей мощности промпласта $2,8-3,2$ м на долю горючего сланца приходится 1,5-1,8 $\boldsymbol{M}$, а на шахтах Ленинградского месторождения эти параметры соответственно $1,8-2,0$ и 1,0 1,1 м. При отбойке промпласта на общую его мощность получается горная масса, состоящая в весовом отношении наполовину из горючего сланца и наполовину из карбонатной породы. Из-за крепкого контакта между сланцевыми и известняковыми слоями в отбитой горной массе образуется большое количество сростков сланца с породой, которые осложняют обогащение, мешают полной механизации добычи и обуслов- 
ливают большие эксплуатационные потери отбитого сланца при современных высоких требованиях к качеству товарного сланца.

Кроме того, в пределах ПСБ промпласт значительно различается по качеству и составу, что обусловливает гри его выемке неодинаковый выход сланцевого продукта разного качества. Например, в южной части Эстонского месторождения на подготавливаемых новых резервных участках общая и полезная мощность промпласта значительно меньше, чем на полях действующих шахт в северной части месторождения, а теплотворная способность чистого сланца по промпласту здесь близка к теплотворной способности всей горной массы, получаемой на действующих шахтах при валовой выемке промпласта на общую его мощность.

Промпласт такого сложного строения необходимо опробовать очень тшательно. Однако имеющиеся многочисленные данные пластового и пластово-дифференциального опробования из-за неодинаковых условий отбора проб и применения разных методик, неодинаково достоверны и не сопоставимы друг с другом. Әто относится к опробованию как по разведочным скважинам, так и по горным выработкам шахт. Главный недостаток в опробовании промпласта сланца заключался в том, что известняковые прослои брались в пробы в разных количествах, в основном по признаку их мощности и независимо от долевого участия в строении сланцевого слоя.

Поскольку известняковые прослои содержатся во всех сланцевых слоях, а в некоторых они составляют по весу $15-20 \%$ (слой С) и даже $40-50 \%$ (слой $\mathrm{F}$ ) и к тому же имеют весьма изменчивую мощность на расстоянии всего нескольких сантиметров, то недостаточно точный учет их в строении промпласта сланца при опробовании неизбежно ведет к неточной оценке запасов и качества сланца в залежи. Без специальной проверки определить эту неточность нельзя, но предположительно она колеблется в пределах $10 \%$, в то время как отклонения в оценке запаcok в настоящее время допускаются в пределах всего лишь $5 \%$.

По-видимому, в дальнейшем при опробовании промпласта необходимо определять мощность, весовые отношения, объемный вес, качество и вещественный состав по чистым разностям горючих сланцев и известняков, в отдельности по каждому слою и по пласту сланца в целом. Такое опробование позволит получать сопоставимые результаты единичных анализов и измерений по пласту, что необходимо для объективного суждения об изменении строения и состава промпласта по площади. Без этого, как без научной основы, нельзя дать правильного геологического и технико-экономического обоснования кондиций на сланец для учета балансовых запасов. Запасы в недрах, несомненно, нужно учитывать по чистому сланцу, без заранее обусловленных потерь и засорения сланца породой при добыче (как это делается сейчас). Только в этом случае и при установлении оптимальных пределов теплотворной способности сланца по промпласту можно организовать и вести на шахтах правильный учет добычи, потерь и движения запасов сланца, а также эффективно бороться за снижение потерь сланца, которые, по отчетным данным сланцедобывающих предприятий, в настоящее время составляют $0,3-0,4$ т на каждую тонну добытого товарного сланца. Мириться с такими потерями сланца нельзя по двум основным причинам. Во-первых, исходя из уже достигнутого высокого уровня добычи и предусмотренного увеличения ее в ближайшие годы, потери сланца в абсолютных величинах достигнут 6-10 млн. $T$ в год, что равноценно пронзводственной мощности нескольких крупных шахт. Во-вторых, резервные участки для закладки новых шахт по геологическим и горнотехническим 
условиям, полезной мощности пласта и качеству сланца в залежи хуже шахтных полей действующих шахт и разрезов.

\section{Зольность и вещественный состав сланца}

При оценке качества всех сортов товарного сланца ПСБ в настоящее время исходят из таких показателей, как теплота сгорания, содержание влаги и размер кусков. К сланцам, в отличие от ископаемых углей, не предъявляется каких-либо особых требований в отношении состава и свойств компонентов, например содержания серы, температуры плавления золы и др. Поэтому в ходе геологоразведочных работ зольность и свойства золы сланца ПСБ изучались недостаточно.

Большая общая зольность товарного сланца ПСБ (60-70\%) создает известные трудности при его сжигании и термической переработке, снижая коэффициент использования установленной мощности агрегатов, и приводит к образованию больших скоплений отходов производства, хранение и транспортировка которых связаны со значительными неудобствами и расходами. В то же время, как это установлено исследовательскими работами многих научіых учреждений и подтверждено практикой, негорючая составная часть кукерситов по химическому составу и свойствам пригодна для производства строительных материалов и для известкования и удобрения кислых почв. Это создает хорошие предпосылки для внедрения в производство метода комплексного и безостаточного использования горючих сланцев, включая их негорючую минеральную часть и переслаивающиеся с ними известняки. При таком использовании сланцевое топливо должно обладать, кроме минимально допустимой теплоты сгорания, также определенным и стабилизированным вещественным составом минеральной части. Например, для целей прямого комплексного производства электроэнергии и клинкера портландцемента пригодно сланцевое топливо, в прокаленной (до $\left.1600^{\circ} \mathrm{C}\right)$ золе которого содержится $62-63 \pm 1 \% \mathrm{CaO}$, а в золе сланцевого топлива, предназначенного для сжигания с жидким шлакоудалением допустимо содержание $\mathrm{CaO}$ в пределах $44-52 \pm 2 \%$. Кроме того, состав золы должен отвечать определенным требованиям цементного производства по силикатному и глиноземному модулям. Фактически в золе производимых в настоящее время сортов товарного сланца содержание $\mathrm{CaO}$ колеблется в пределах $46-56 \%$.

Подготовка сланцевого топлива с заданным составом и свойствами зольной его части значительно затрудняется показанным выше сложным строением промпласта. Зольность товарного сланца слагается из зольности чистых разностей самих горючих сланцев и засоренности сланца известняковой породой, находящейся в составе сланцевых кусков (в виде тончайших прослоек и линз, заполненных ходов илоедов, стяжений и конкреций, скелетных остатков ископаемых животных) или в виде отдельных кусков разной величины. Содержание $\mathrm{CaO}$ в прокаленном остатке известняков и кукерситов, взятых из разных слоев, различное и изменяется в первом случае от 65 до $90 \%$, а во втором от 30 до $50 \%$. Следовательно, состав и свойства золы сланцевого топлива зависят от величины его зольности. Чтобы определить, при каких соотношениях горючего сланца и известняковой породы и из каких слоев легче и дешевле получить сланцевое топливо с заданными составом и свойствами золы, требуется хорошо знать, помимо строения промпласта, также вещественный состав и физико-механические свойства всех слагающих его разновидностей сланца и известняков. Знание 
вещественного состава и свойств минеральной части горючих сланцев и сопутствующих им известняков позволит правильнее оценить ресурсы ПСБ и будет способствовать более рациональному их использованию.

\section{Размывы. Тектоника. Карст}

Промышленный пласт горючих сланцев ПСБ, как уже говорилось, приурочен к постоянному уровню в стратиграфическом разрезе и залегает в толще вмещающих пород сообразно их общей параллельной слоистости и моноклинальному падению на юго-юго-восток в среднем под углом около $1 / 4$ градуса, следуя погружению поверхности кристаллического фундамента. Эта первичная форма элементарной структуры и определяет простое геологическое строение бассейна: на севере неглубокое залегание промпласта, где его распространение ограничивается в западной части выходом на дневную поверхность под маломощные четвертичные отложения, а в восточной части - размывом перед девонской трансгрессией; в южном направлении промпласт сланца постепенно погружается и одновременно, в связи с фациальными изменениями в области осадконакопления, генетически выклинивается. Однако такое простое геологическое строение бассейна осложняется размывами промпласта, тектоническими нарушениями, трещиноватостью и закарстованностью пород, а также брахискладками и неровностями гипсометрии подошвы промпласта. Эти факторы отрицательно влияют на освоение бассейна: они уменьшают устойчивость пород кровли и почвы в горных выработках, способствуют обводнению шахт, ведут к увеличению потерь сланца, ограничивают выбор направлений горных выработок и вынуждают производить подготовительные горные выработки в бо́льшем объеме.

Размывы промпласта, повсеместно развитые вдоль северной границы бассейна, собственно и определяют эту границу. Для горной практики здесь особое значение имеют глубокие размывы ордовикских отложений (до промышленного пласта сланца и ниже) по древним эрозионным долинам, заполненным водонасыщенным, преимущественно песчано-галечным материалом четвертичного возраста. Три наиболее крупные из них развиты на площади Эстонского месторождения. Это Кундаская, Пуртсеская и Вазавереская долины, получившие свое название по наименованию рек, текущих здесь параллельно им и частично совпадающих с ними в плане. Долины расположены друг от друга на расстсянии $20-25 \kappa м$. Размыв промпласта сланца в погребенных долинах прослежен буровыми скважинами на протяжении до $18 \kappa$, на юг от северной границы месторождения в виде полос шириной $0,5-1,5 \kappa м$ и местами до $4 \kappa м$; долины расширяются и углубляются в северном направлении. Общая мощность песчано-галечных отложений в долинах превышает 50 , а мощность их выше уровня залегания промпласта сланца достигает 30 м. Эти долины, являющиеся естественными рубежами сланцевой залежи, учитываются при раскройке шахтных полей и разработке комплексных схем вскрытия месторождения.

Горные выработки некоторых шахт (№ 10, «Кивиыли») уже близко подходят к техническим границам шахтных полей, проходящим вдоль таких погребенных долин, в которых промпласт сланца размыт. Расстояния от технических границ шахтных полей до линии размыва промпласта в погребенных долинах здесь местами достигают $1 \kappa м$, что для охранных целиков, вероятно, слишком много и приводит к неоправданно большим потерям сланца по геологическим причинам. В целях 
наиболее полного извлечения запасов сланца из недр в таких местах необходимо изучить погребенные долины с точки зрения безопасности ведения подземных горных работ (обрушение кровли, притоки воды и др.).

Зоны тектонических нарушений тоже мало изучены, так как горными выработками они еще не вскрыты, и суждения о их размерах и строении основываются лишь на данных разведочного бурения и электроразведки, по которым общими признаками для них являются: значнтельная протяженность, измеряемая десятками километров; сравнительно большая ширина - от десятков до сотен метров; сильная трещиноватость пород в их пределах, а также их доломитизация, закарстованность, местами смятие и перемещение по вертикали на $10-20 \mathrm{~m}$. На Эстонском месторождении выявлены три большие зоны тектонических нарушений: в западной части - Азериское, в центральной Ахтмеское и в восточной - Вийвиконнаское нарушение. Все эти нарушения имеют северо-восточное простирание, но они не строго пара.Iлельны друг другу: минимальное расстояние между Вийвиконнаским и Ахтмеским нарушениями - 8 км и максимальное - между Ахтмеским и Азериским нарушениями - 32 кл. К Азерискому с запада примыкает нарушение широтного простирания до 500 м в ширину, с приподнятым примерно на 5 м северным крылом (Вахер и др., 1962).

По этим зонам нарушения, вероятно, произошло блоковое смещение всей развитой здесь осадочной толщи палеозоя. Они обрезают сплошное распространение промышленного пласта сланца и усложняют гипсометрию его подошвы; по ним более интенсивно циркулируют подземные воды и осуществляется гидравлическая связь между водоносными горизонтами; в их пределах нарушена первоначальная монолитность пород и породы видоизменены. Все это заставляет рассматривать их, подобно названным выше погребенным эрозионным долинам, как естественные границы шахтных полей.

До сих пор не решен вопрос, как и в отношении погребенных долин, о возможности и целесообразности отработки очень больших запасов сланца в пределах самих зон тектонических нарушений и в прилегающих к ним пограничных участках месторождения.

Трещиноватость пород интенсивно развита и вне зон тектонических нарушений. Повсеместно имеются тектонические трещины широтного, меридионального, северо-восточного и северо-западного направлений, обычных для Русской платформы. Эти трещины захватывают всю развнтую здесь разновозрастную осадочную толщу пород. По основным морфологическим признакам (залегание, близкое к вертикальному; прямолинейность; прямые неровные стенки, обычно без следов скольжения) они относятся к трещинам отрыва. Трещины каждого из указанных направлений по-разному влияют на условия ведения горных работ. Менее развиты и оқазывают наименьшее влияние на горнотехнические условия ортогональные трещины, обычно сомкнутые. Трещины северо-восточного простирания (средний азимут 50-60) построены сложно: они бывают открытые и заполненные песчаным материалом н кальцитом с сульфидами; по этим трещинам развит «древний карст». Ширина открытых трещин обычно меньше 1 cм. Они частично заполнены обломками пересекаемых ими пород; стенки их местами покрыты щетками кристаллов кальцита и пирита. Расстояние между открытыми трещинами в среднем около 130 м, но местами они группируются по $2-5$ и более на расстоянии десятка или двух-трех десятков метров; в этой полосе обычно развиты карстовые процессы и связанные с ними перемещения пород, незначительные по единичным трещинам, но по 
мнсгим трещинам составляющие суммарно до $2-3$ м. Закарстованные зоны по трещинам северо-восточного простирания широко развиты в бассейне. Во многих случаях они вскрыты вкрест их простирания преимущественно подготовительными горными выработками шахт. Ширина такой одинарной зоны вкрест ее простирания обычно несколько десягков метров. Наиболее изменены и деформированы породы в осевой части закарстованной зоны, где вместо горючего сланца промышленного пласта залегают остаточная глина, обломки доломитов и доломитизированного известняка (собственно «древний карст»). Область замещения горючего сланца остаточной глиной по промпласту вкрест простирания закарстованной зоны измеряется расстоянием от долей метра до нескольких десятков метров. «Древние карсты» по простиранию прослеживаются на расстоянии от сотен метров до нескольких километров, и их исчезновение и появление вновь через какой-то интервал не подчиняется какой-либо видимой закономерности. Расстояние между «древними карстами» вкрест их простирания равно от 0,5 до 3 и более километров.

«Древние карсты» по протяжению местами переходят в трещины, заполненные песчаником с кальцитовым и пиритовым цементом (местное название «трещины-жилы»). По-видимому, «древний карст» и «трещины-жилы» генетически взаимосвязаны. Мощность «трещин-жил» колеблется от долей сантиметра до 20 см. «Древний карст» и открытые трещины северо-восточного простирания усиливают обводненность шахт. Половина трещин северо-восточного простирания, вскрываемых горными выработками шахт, обводнена, особенно со стороны невыработанного массива; вода из них поступает в виде капежа и небольших струй.

Трещины северо-западного простирания (средний азимут $300-320^{\circ}$ ), вскрываемые горными выработками шахт, частью закрытые, а мощность открытых равна нескольким миллиметрам. Расстояние между трещинами обычно от нескольких метров до десятков метров. Эти трещины существенно влияют на обводнение горных выработок, и от них зависит устойчивость кровли: половина вскрываемых горными выработками трещин обводнена (капеж и струи, особенно в направлении движения забоя), и обычно по ним идет блоковое обрушение пород кровли.

В зависимости от степени трещиноватости и закарстованности, на шахтах имперически устанавливается. граница опасного ведения подземных работ и применяется сплошное или усиленное крепление кровли выработок, а местами и боковых стенок. Закарстованные и тектонически нарушенные зоны остаются в целиках, что ведет к потере сланца в недрах и к производству дополнительных подготовительных и нарезных горных выработок.

В условиях неглубокого залегания промпласта сланца значение имеют в качестве горногеологического фактора трещины выветривания и трещины, образовавшиеся в перекрывающей толще известняков при ведении горных работ, по которым происходит инфильтрация атмосферных осадков и вод поверхностного стока.

Оценка влияния (в количественном выражении) зон тектонических нарушений и закарстованных зон на себестоимость добычи и полноту извлечения запасов сланца по ПСБ еще не произведена. Это необходимо сделать в практических целях, учитывая, например, высокую степень трещиноватости и закарстованности вмещающих пород и самого промпласта сланца. Так, по наблюдениям в действующих шахтах, породы на уровне ведения горных работ разбиты системой вертикальных тектонических трещин северо-восточного и северо-западного простирания на блоки размером примерно $30 \times 150$ м и на $5-10 \%$ от их пло- 
щадного распространения охвачены карстовыми процессами. На общей площади выработанного на Ленинградском месторождении пространства $\left(25 \kappa \mu^{2}\right)$ по четырем шахтам горными выработками вскрыто более 70 закарстованных зон общей протяженностью около $50 \kappa м$ при ширине одинарных и сближенных зон вкрест их простирания от нескольких метров до 200 м. Штреки, идущие вкрест простирания закарстованных зон, вскрывают эти зоны на шахтах Ленинградского месторождения через каждые 0,5-0,6 км, а на шахтах Эстонского месторождения через каждые $1,0-1,2 \kappa м$.

Складчатые формы нарушения установлены геологоразведкой в северо-западной части Эстонского месторождения. Здесь в $6 \kappa$ к востоку от Азериского тектонического нарушения, около озера Ульясте, имеется пять небольших прерывистых брахиантиклиналей, расположенных на площади 45-50 км². По первой внешней замкнутой стратоизогипсе подошвы промпласта горючего сланца самое крупное поднятие имеет площадь $3,5 \kappa \mu^{2}$, а наименьшее - 1,5 $\kappa \mu^{2}$. Амплитуда поднятий по уровню залегания промпласта сланца максимально 20 м. Углы падения пласта сланца по крыльям складок не превышают $3^{\circ}$. В сводовых частях складок промпласт, залегающий под четвертичными отложениями, разрушен на площадях размерами до $0,5 \times 0,5 \kappa$. . В этом же районе, примерно в 2 км к востоку от Азериского тектонического нарушения, буровыми скважинами оконтурена единичная брахисинклиналь размерами по первой внешней замкнутой стратоизогипсе подошвы промпласта горючего сланца $2,2 \times 1,5 \kappa$. В центре этой синклинальной складки промпласт сланца опущен на 50 м. Литологических изменений по промпласту горючего сланца в пределах указанных выше брахискладок не установлено.

В северо-западной части Эстонского месторождения, на участке развитых брахискладок и вплоть до Азериского тектонического нарушения, следует ожидать более сложных условий разработки месторождения по сравнению с другими участками.

Являются ли описанные здесь брахискладки изолированными образованиями, или они входят в какой-то комплекс тектонических форм высшего порядка, еще не выяснено. Но последнее предположение вполне вероятно, судя хотя бы по их местонахождению относительно Азериского нарушения и примыкающего к нему тектонического нарушения широтного направления. Подобная ульястеским поднятиям, но более крупная брахиантиклиналь разбурена скважинами за пределами северной границы Әстонского месторождения, в районе Синимяэ, у скрещения Ахтмеского и Вийвиконнаского тектонических нарушений. Возможно, что образование неровностей гипсометрни подошвы промпласта сланца, слабо обнаруживаемых на участках детальной разведки буровыми скважинами по сетке $500 \times 500$ м и отчетливо выявляемых нивелировкой при маркшейдерских замерах в горных выработках шахт, также обусловлено явлениями тектонического характера.

Эти неровности на общем фоне падения промпласта на юго-юговосток характеризуются следующими особенностями. Изогипсы весьма извилисты и отклоняются в обе стороны от условной прямой на плане без какой-либо закономерности. Так, например, горизонтали через 2 м то приближаются друг к другу на расстояние до $100 \mu$, то удаляются на расстояние до 1 км. Горизонтали через 2 м, насколько об этом можно судить по площадям выработанного пространства на отдельных шахтах $\left(15-20 \kappa м^{2}\right)$, за исключением единичных случаев, не замыкаются. На пространстве между этими горизонталями обычно вырисовываются замкнутые по контуру возвышения и понижения размерами 
в поперечнике $50-750$, с амплитудой $0,5-1,5$ м. Каких-либо закономерностей в размещении таких возвышений и понижений не установлено. Отметим лишь, что гипсометрия подошвы промпласта сланца усложняется вблизи тектонических нарушений и закарствованных зон, что может служить указанием на образование неровностей в залегании промпласта сланца в результате блочного смещения осадочной толщи пород.

Описанные неровности в залегании промпласта кажутся незначительным горногеологическим фактором, но они несомненно отрицательно влияют на себестоимость добычи сланца, поскольку осложняют водоотлив из забойного пространства, что ведет к повышению влажности сланца при его добыче и к ухудшению условий работы в забое (Зысин, 1967).

\section{Обводненность шахт. Физико-механические свойства пород}

Гидрогеологические условия ПСБ выявлялись, как и описанные выше тектонические нарушения, по мере его промышленного освоения. Об обводненности шахт можно судить по следующим данным. По всему бассейну за один год послевоенного периода откачивалось шахтных вод в среднем более $80 \mathrm{mлн.} \boldsymbol{M}^{3}$, а среднегодовая добыча сланца за этот период по бассейну составила 10 млн. т. Таким образом, коэффициент водообильности шахт равен $8 \mathrm{~m}^{3} / \tau$. Это обусловливает увеличение себестоимости добычи сланца не менее чем на 10\% (Сооп и др., 1966).

Сложные гидрогеологические условия ПСБ объясняются нахождением его в пределах крупного артезианского бассейна со значительными ресурсами подземных вод, слабой расчлененностью поверхности, небольшой мощностью четвертичных отложений, приуроченностью сланцевой залежи к трещиноватой и закарстованной ниже современного базиса эрозии известняковой толще, относительно большим количеством атмссферных осадков.

Здесь развиты грунтовые воды четвертичных отложений и подземные воды, приуроченные к трещинам в породах кристаллического фундамента, к песчаным отложениям протерозойского и кембрийского возраста и к пористо-трещинным карбонатным породам ордовикского возраста.

Четвертичные грунтовые воды приурочены к современному аллювию, водно-ледниковым, ледниковым и болотным отложениям. Эти отложения характеризуются небольшой мощностью, невыдержанным распространением и большей частью глинистым составом. Особо следует выделить лишь воды песчаных и гравийных водно-ледниковых отложений описанных выше древних эрозионных долин. Болотные воды пока не создавали больших препятствий для разработки месторождений.

Шахтные воды питаются преимущєственно подземными водами из перекрывающих пород среднего и верхнего ордовика и в меньшей мере из пород подстилающей толщи.

Обводнение мелких шахт глубиной до 40 м связано главным образом с режимом поверхностного стока и обусловлено повышением горизонта подземных вод за счег атмосферных осадков, а также попаданием поверхностных вод в горные выработки через шурфы, разведочные скважины, трещины оседания над выработанным пространством, через тектонические трещины и карстовые полости. Повышение уровня подземных вод и вместе с тем значительное увеличение притока шахтных вод происходит в связи со снеготаянием в первой половине апреля, 
после чего наступает более плавный спад, продолжающийся до июня-июля. Атмосферные осадки летом и осенью также повышают уровень подземных вод и увеличивают приток воды в горные выработки, но в меньшем количестве. Коэффициент сезонной неравномерности притока воды на мелких шахтах достигает 20 и более. С увеличением глубины шахт этот коэффициент резко снижается и при глубине более $70 \mu$ не сказывается. Статические запасы подземных вод в общем количестве тритока воды в мелкие шахты глубиной до 40 м составляют не более $3 \%$; динамический поток подземных вод составляет $25-45 \%$ от общего количества притока шахтных вод; остальная, основная часть притока шахтных вод приходится на воды поверхностного стока.

Водообильность шахт Эстонского и Ленинградского месторождений, по данным многолетних наблюдений шахтной геологической службы, характеризуется следующими показателями (см. табл. 2):

Таблища 2

\begin{tabular}{|c|c|c|}
\hline \multirow{2}{*}{ Показатели } & \multicolumn{2}{|c|}{ Шахты месторождений } \\
\hline & Эстонского & Ленинградского \\
\hline Сүеднегодовой часовой приток, $\boldsymbol{\mu}^{3} / \boldsymbol{u}$ & $400-2400$ & $500-600$ \\
\hline Среднемаксимальный приток, $\mu^{3} / u$ & $4000-10000$ & $100-1800$ \\
\hline Коэффициент водообильности, $M^{3} / T$ & $5-14$ & $5,5-7,5$ \\
\hline $\begin{array}{l}\text { Приток на единицу площади вырабо- } \\
\text { танного пространства, } \varkappa^{3 / 4} \text { на } 1000 \mu^{2}\end{array}$ & $0,1-0,8$ & $0,01-0,2$ \\
\hline
\end{tabular}

Несмотря на большой объем выполненных гидрогеологических работ, вопрос об эффективных способах борьбы с шахтными водами в ПСБ до сих пор не решен. В частности, это касается предварительного осушения шахтных вод, изоляции прорывов воды в горных выработках шахт и обратной циркуляции откачанных вод в шахты. Гидрогеологические исследования на шахтах ПСБ необходимо продолжать и совершенствовать.

Физико-механические свойства пород промпласта сланца и перекрывающей толщи, от которых зависит характер проявления геомеханических процессов при ведении подземных горных работ (устойчивость кровли и целиков и т. п.), мало изучены. Достаточно, к примеру, сказать, что отсутствие достоверных данных об объемном весе пород перекрывающей толщи и о механических свойствах пород промпласта сланца не позволяет производить на шахтах расчет оптимальных размеров поддерживающих целиков и выемочных площадей, что, несомненно, отрицательно сказывается на величине потерь сланца при добыче, особенно в местах, тяготеющих к геологически нарушенным зонам.

\section{Заключение}

По Прибалтийскому сланцевому бассейну еще остались недостаточно изученными многие охарактеризованные выше геологические и горнотехнические факторы, знание которых необходимо в интересах наиболее полного извлечения запасов, безопасного ведения горных рабст и рационального использования сланцевых ресурсов. Детальная характеристика этих факторов необходима для решения следующих наиболее актуальных вопросов: геологического и технико-экономического обоснования кондиций на горючий сланец; установления опти- 
мальных общих и эксплуатационных потерь сланца на шахтах и карьерах; разработки мероприятий по предотвращению потерь сланца, не связанных с какими-либо необходимыми функциями (потери отбитого сланца, потери из-за неправильного ведения горных работ, завышенные размеры охранных целиков, неоправданно завышенные требования готребителей к качеству товарного сланца и др.); ведения на шахтах кравильного учета добычи, потерь и движения запасов; эффективной борьбы с шахтными водами; получения исходных инженерно-геологических данных для правильного управления горным давлением и охраны подземных горных выработок от обрушения; максимальной отработки запасов на участках, тяготеющих к зонам тектонических нарушений и древним погребенным долинам; определения степени влияния геологических и горнотехнических факторов (крепость пород, объемный вес, трещиноватость, тектонические нарушения, обводненность и др.) на себестоимость добычи сланца и на полноту извлечения запасов (Бауков и Кельпман, 1967).

Для решения этих вопросов нужно привлечь специализированные организации при обязательном активном участии местной шахтной геологической службы.

\section{Л И ТЕ РА Т У РА}

Ба уков С., Кельпм ан Я. 1967. Требования к геологической разведке Эстонского месторождения горючих сланцев. Горючие сланцы, № 4, 9-12.

Быховер Н. А. 1967. Экономика минерального сырья. М., «Недра».

В ахер Р. М., Пуура В. А., Эрисалу Э. К., 1962. Тектоническое строение Северо-Восточной Эстонин. Тр. Ин-та геол. АН ЭССР, 10. Геологня палеозол, 319-332.

В ийлуп В., П а альме Г., Аллик А. 1967. О перспективах и проблемах добычи сланца в ЭССР. Горючие сланцы, № 4, 6-8.

3 ысин А. А. 1967. Анализ особенностей изменчивости основных геолого-промышленных параметров Ленинградского месторождения горючих сланцев, Изв. АН ЭССР. Химия * Геология, 16, № 4, 330-338.

Мельников Н. В. 1966. Минеральное топливо. Технико-экономический очерк развития топливной промышленности СССР. М.

Сооп К., То омик А., Т алве Л. 1966. Влияние обводненности горных выработок на себестоимость сланца. Сланцевая и хим. пром., № 6, 6-8.

50 лет сланщедобывающей промышленности Эстонской ССР. Сб. статей. Таллин, «Валгус», 1966.

Институт геологии

Академии наук Эстонской ССР
По́ступила в редакцию 2/II 1968

\section{S. BAUKOV}

\section{BALTI POLLVKIVIBASSEINI GEOLOOGILIS-TÖOOSTUSLIKU HINNANGU KRITEERIUMID}

Oma suurte kvaliteetsete põievkivivarude ja odava kaevandamisviisi tōttu on Balti pōlevkivibassein NSV Liidu loodeosas üheks suuremaks toorainebaasiks elektrienergia ja kunstliku kütuse tootmisel, samuti väga eriilmelisele keemiatööstusele.

Artiklis kirjeldatakse põhjalikumalt mitmeid looduslikke tegureid, mis raskendavad basseini tööstuslikku kasutamist, nagu tootliku kihi keeruline ehitus, pôlevkivi kõrge tuhasisaldus, tootliku kihi, tema lasumi ja lamami suur lōhelisus ning karstumine, tootliku kihi uhtumine maetud orgude tekkel, kaevanduste ja karjääride tugev üleujutamine.

Nende tegurite detailne uurimine võimaldaks lahendada mõned praktilise iseloomuga küsimused, nagu pōlevkivikadude vähendamine ekspluatatsioonil, pōlevkivitootmise omahinną alandamine ja mäetööde ohutuse suurendamine. 


\section{S. BAUKOW}

\section{KRITERIEN FUR EINE GEOLOGISCH-INDUSTRIELLE EINSCHÄTZUNG DES BALTISCHEN BRENNSCHIEFERBASSINS}

Dank den großen Vorräten hochwertigen, leicht abbaubaren Brennschiefers ist das baltische Brennschieferbassin im nordwestlichen Teil der Sowjetunion eine der größten Quellen elektrischer Energie, künstlicher Brennstoffe und der verschiedensten Rohmaterialien für die chemische Industrie.

Der Artikel bringt eine ausführliche Charakteristik der natürlichen Faktoren, welche die industrielle Nutzung des Bassins erschweren, so besonders: die komplizierte Struktur der brennschieferführenden Schicht, der hohe Aschengehalt des Brennschiefers, die Zerspaltung und Verkarstung des Hangenden und des Liegenden, die Zerschwemmung der brennschieferführenden Schicht bei der Entstehung der Urstromtäler, die Oberschwemmung der Bergwerke.

Eine ausführliche Untersuchung der genannten natürlichen Faktoren würde die Losung einer Reihe von Fragen praktischen Charakters ermöglichen, wie z. B. die Verminderung der Abbauverluste, die Senkung der Produktions-Selbstkosten und die Verbesserung der Arbeitssicherheit. 